\title{
Benefits of Aviation Weather Services: A Review of International Literature
}

\author{
Kwabena Asomanin Anaman ${ }^{1}$, Ruth Quaye ${ }^{1}$ \& Bernice Owusu-Brown ${ }^{2}$ \\ ${ }^{1}$ Economics Division, Institute of Statistical, Social and Economic Research, University of Ghana, Legon, Accra, \\ Ghana \\ ${ }^{2}$ Department of Economics, University of Ghana, Legon, Accra, Ghana \\ Correspondence: Kwabena Asomanin Anaman, Professor, Economics Division, Institute of Statistical, Social and \\ Economic Research, University of Ghana, Legon, Accra, Ghana.
}

Received: April 24, 2017

doi:10.5430/rwe.v8n1p45
Accepted: May 9, 2017

Online Published: May 26, 2017

URL: https://doi.org/10.5430/rwe.v8n1p45

\begin{abstract}
This paper presents a summary of the international literature published on the benefits of aviation weather services. Aviation operations are highly sensitive to weather conditions. Information on weather conditions helps meteorologists, pilots, navigators, airline companies and businesses to ensure safe flights and save money by reducing some of the stringent requirements related to carrying extra fuel loads. The development of constantly updated flight plans with respect to available weather information regarding changing wind and general weather conditions can enable aircraft to use fuel more efficiently and navigate their planes in safer environments that avoid turbulence and make air flights comfortable to the travelling public. The summary literature presented in this paper illustrates the importance of the work of meteorologists in the production of relevant information and data that are accessible to pilots and navigators. The pooling of meteorological information, data and other resources by member countries of the World Meteorological Organisation represents a classic case of international cooperation that has ensured relatively safe and comfortable air flights across the world since the era of international air travel in the $20^{\text {th }}$ Century speeding up the process of the more historically-recent globalisation.
\end{abstract}

Keywords: airline economics, aviation industry, aviation weather services, economics of meteorological services, transportation economics

\section{Introduction}

Weather services are produced by National Meteorological and Hydrological Services (NMHS). NMHSs of 191 countries in the world are members of the World Meteorological Organisation (WMO). The WMO is responsible for the pooling of weather and climate data information and sharing activities among its member countries including information for safe and reliable air navigation across the globe. The successful international cooperation carried out under the auspices of WMO has been responsible for the widespread access of the public to international flights across the globe and the development of the aviation industry as an important component of national economies and international trade (Shun et al., 2009). The aviation industry is a critical component of the economy of industrialised countries such as United States; for landlocked countries and countries with limited road infrastructure such as Ethiopia, and small island nation states, the aviation industry is an indispensable vehicle for advancing economic growth and sustainable development. The aviation industry is also an important driver of the growth of other economic activities such as domestic trade, military operations and tourism. The Air Transport Action Group (2016) estimates that the aviation industry accounted for 664.4 billion dollars in direct gross benefits and supported about 2,700 billion dollars of activities accounting for about 3.5\% of the world's gross domestic product (GDP) in 2014.

The work of NHMSs includes the development and timely distribution of weather forecasts, information and early warnings of extreme events provision of data, information and products required for various economic sectors such as agriculture, health, energy, infrastructural planning and development, settlement management and the transport sector (WMO, 2015; Leviäkangas and Hautala, 2009; Campos et al., 1999; Anaman and Lellyett, 1996a; Sear et al., 1996). For the transport sector, civil aviation and marine sub-sectors are particularly dependent on accurate and reliable weather information. The benefits of weather information to the aviation sector are considerable as the aviation industry is known to be both very weather-sensitive and weather-information-sensitive (Marks, 1980; Anaman et al., 
1998; Leigh et al., 1998; Guzman, 1999; Anaman et al., 2000; WMO, 2014). This implies that while weather phenomena considerably affect aviation activities, weather information can be used to minimise weather impacts. Aviation weather information include aerodrome weather reports, terminal and end route forecasts, weather warnings and meteorological advice to air traffic controllers (Australian Commonwealth Competitive Neutrality Complaints Office (ACCNCO), 2001). The Ghana Meteorological Agency (GMET), an NHMS, provides information and warnings on approaching weather on a 24-hourly basis and issues terminal aerodrome forecasts on a six-hourly basis. Other services provided by GMET include aerial weather summary for search and rescue activities (GMET, 2017).

Although weather information is generally classified as a public good and is often made freely available to the general public and a variety of business consumers, for the aviation industry, weather information is largely an exclusive and "rival-in-consumption" good as airlines pay for this service (Leigh et al., 1998; Anaman et al., 2000, WMO, 2015, South African Government Department of Environmental Affairs, 2016). The benefits of weather information to airlines rest on the important role such information plays in the safe navigation of aircraft from and across different geographical points. Safety regulations related to possibility of adverse conditions are strictly enforced by national and international laws for which airlines are required to comply with. Another benefit of weather information is the savings in fuel that can be derived from the judicious use of forecasts on winds to propel aircraft faster in flights.

A profitable and economically sustainable organisation requires continuous efforts at achieving profits which involve lowering costs and/or raising revenues. For the aviation industry, the revenue side of the airline profit equation is constrained by government security taxes, unhealthy competitive practices and the frequent entrance of low cost carriers into the industry. Given the volatile international world market conditions regarding crude oil over the last four decades, since the October 1973 Arab-Israeli War, airlines have struggled to maintain sustainable profits. An important factor in the achievement of sustainable profits has been the high costs of fuel, a critical and necessary requirement for safe aviation for which there is little room to cut expenses. However, the volatile international oil market conditions have forced airlines to be more creative in reducing cost. One of such innovative practices airlines have adapted to increase the profit margin of their shareholders is to slash costs in all aspects of the productions which have included the careful use of high quality weather information to reduce some of the stringent requirements for added fuel without sacrificing safety (Qantas Airways Corporation, 1993; Leigh et al., 1998; Anaman et al., 2000).

This review of the literature on aviation weather services is a component of our larger study on economic and social benefits of meteorological services. This review is necessitated by the world-wide importance of the aviation industry in both developing and developed countries. Aviation weather services play an indispensable role in the functioning of the aviation industry as it is now largely unthinkable that a commercial aircraft can fly around the world without weather information. The historically-recent wave of globalisation has been made possible largely due to the extensive movements of aircraft around the world made possible by new technologies and improved weather information. We consider this review as a good starting point for our larger study on the economic and social benefits of meteorological services. Other types of meteorological services, such as agricultural and mining weather services, are also important but they tend to more useful to people in localised situations and specific geographical zones; refer to Anaman and Lellyett (1996b) for impacts of enhanced weather services for agriculture in New South Wales, Australia; and Anaman and Lellyett (1997) for the benefits of public weather services for the mining industry in Queensland, Australia. On the other hand, aviation weather services and information are universally shared among individuals, airline companies, navigators, civil and military pilots and national meteorological agencies around the world.

With the completion of a basic introduction to aviation weather services and the importance of the aviation industry, the remainder of this paper is structured around several themes. The next section is a brief discussion of the various types of meteorological services produced by NMHS for the aviation industry. This section is followed by a review of the benefits of aviation weather services in terms of reduction in fuel cost savings, the role of weather information in ensuring the safety of aircraft, and other benefits of aviation weather services such as their use in flight planning, the management of airports, and the reduction of environmental impacts. The fifth section is devoted to the costs of acquiring and the related direct economic benefits of aviation weather services for airline companies. The sixth and final part of this paper discusses the conclusions and then provides a list of cited references used in the paper.

\section{Types of Weather Services and Information Supplied to the Aviation Industry}

NHMSs have strong and long-term relationships with the aviation industry due to the importance of the services that they provide to the aviation industry dating back to the first aviation flight originating in the United States (WMO, 2015; Shun et al., 2009). Weather services provided to the aviation industry come in two forms. These are (1) general services and (2) customised services which are provided according to the specifications and needs of an airline operator and at an agreed cost (Office of the Federal Coordinator of Meteorological Services and Supporting Research 
(OFCMSSR), 2014; GMET, 2017; Uganda National Meteorological Authority, 2017). The services and information provided can also be categorised into two types. These are (1) flight planning services and (2) in-flight advisory services (Aviation Weather Centre, 2017a). The information that is released through these services are current weather observations, analysis, forecasts, warnings (in-flight advisories and nowcasting or current to immediate weather forecasts within 30 to 60 minutes), and climatology (Shun et al., 2009). Other services include meteorological reporting service, meteorological watch services and dissemination of information (Shun et al., 2009). These services are provided concurrently or as part of a process which depends on the urgency of the information.

The Federal Aviation Administration (FAA) of the United States (2014) indicates that weather observations comprise the collection of weather information directly or remotely through the use of technological tools and human skills. These observations, when properly analysed and explained, result in a better interpretation of the observation in real terms (FAA, 2014). Forecasts are developed by the application of mathematical models to already observed weather data. FAA (2017) notes that warning information about various adverse events is an important service rendered to the aviation industry given that the largest cause of the delay in the air space system of the United States is the weather. These warnings concern normal weather elements such as wind turbulence, cloud and temperature. According to Shun et al. (2009), warnings may be issued for information on other phenomena that have direct impacts on the weather such as volcanic ash and tropical cyclones which can affect safety in the aviation industry.

Other services provided by national meteorological agencies include telecommunication and dissemination services (Shun et al., 2009; OFCMSSR, 2014; GMET, 2017; Uganda National Meteorological Authority, 2017). Dissemination, as used for meteorological services, refers to the act of sending out a complete report of weather observations to end users, airline operators and pilots (OFCMSSR, 2005). However, given that the weather has the tendency to change rapidly within any minute, and the possible variation in the magnitude of any of the weather elements, plus the difficulty in precisely measuring the intensity of some of the weather events, such as turbulence, volcanic ash and visibility, national meteorological services interconnect and pool their activities with WMO and International Civil Aviation Organisation (ICAO) to provide timely and accurate information especially for international flights (Shun $e t$ al., 2009). These reports are delivered to pilots by use of automated and internet-based methods such as satellites, electronic mails and text messages. Manual and face-face methods of distributing flight information are gradually being phased out in many parts of the world (IMD, 2017; Shun et al., 2009).

Weather information dissemination in aviation comes with the production of reports which are delivered to airline operators. The information given to airlines may be directed for use by airlines which operate within the area of the weather station or for airlines which operate outside the range of the weather station (OFCMSSR, 2014). The information included in the reports include, but are not limited to route forecasts, wind and temperature forecast, volcanic ash advisories/graphics and landing forecasts (OFCMSSR, 20005; GMET, 2017; IMD, 2017) All of these information products help to improve the aviation industry as they offer timely information on the weather to improve safety and guide flight planning. Reports that are based on observations are the aviation routine weather report and the aviation selected special weather report.

The aviation routine weather report, also known as the Meteorological Aerodrome Reports (METAR), deals with weather information observed around the air field and are issued within a 12 to 18 hours interval (Shun et al., 2009). Aviation selected special weather report (SPECI) are issued in between two METAR observations. In some airports, a weather report called Trend Type Forecast (TTF) is issued every two or three hours to indicate significant weather changes that have been observed after the METAR was sent out (Shun et al., 2009). Reports that are based on weather forecasts include the Terminal Aerodrome Forecasts (TAF), while on-coming bad weather warnings come in the form of SIGMET (intended for thunderstorms), SIGMET for convection (which deals with turbulence, volcanic ash, dust storms and sand storms), AIRMET and urgent Pilot reports which are directed at improving in-flight safety against the weather (Shun et al., 2009; AWC, 2017b). This information is sent to airlines using international satellites dedicated to the ICAO and global telecommunication networks (Shun et al., 2009).

TAFs are predictions of the meteorological conditions, usually ranging between 6 and 24 hours, for the airspace within an eight kilometre radius of an aerodrome (Shanahan, 1973). They are a legal requirement for airlines to obtain before their planes can take off for flights (Australian Bureau of Meteorology, 1981). TAFs usually have predictions of wind velocity, visibility, cloud height and type, plus any weather events such as rain, thunderstorms, dust storms, fog and any other meteorological occurrences which may affect the safe operations of aircraft in the vicinity of the aerodrome, especially take-offs and landings. Information of adverse conditions indicated by TAFs for destination aerodromes would imply a legal requirement to uplift for either holding (that is enough fuel to circle the destination airport for a prescribed period) or for flight to an alternative airport (alternate fuel) predetermined before 
take-off (Anaman et al., 2000). With reliably accurate TAF information, some airlines choose not to upload the extra fuel for possible adverse weather conditions, the so-called ALTENATE FUEL, when the forecasts indicate lack of adverse conditions at the destination airport (Qantas Airways, 1993; Leigh, 1995; Anaman et al., 2000). In terms of details of information provided, TTFs are close to TAFs with the TTFs being the updates of the relevant TAFs. Given the rapidly changing weather conditions that can occur in any geographical area, the possibility of degradation of TAFs in terms of their usefulness implies that TTFs often supersede TAFs in terms of overall usefulness to the pilot.

The estimated annual accuracy of TAFs for the four Australian international airports of Brisbane, Perth, Melbourne and Sydney was established over the 22-year period from 1972/73 to 1993/4 by Anaman et al. (1998); the correct annual accuracy averaged $87.6 \%$ with a standard deviation of $1.7 \%$. Further, the proportion of no alternate fuel required TAF forecasts, that actually did require the lifting of alternate fuel, due to actual occurrence of adverse weather conditions at the destination airports, averaged only $1.8 \%$ of all TAF forecasts for the four airports over the 22-year period (Anaman et al., 1998). The 1.8\% figure represented the maximum proportion of flights that would have been diverted to alternate destination airports if the alternate fuel for possible adverse weather conditions had not been loaded by the aircraft before takeoff (Anaman et al., 1998, pp. 106-110).

In a summary, terminal forecasts such as TAFs and TTFs deal with weather conditions covering the geographical area within the vicinity of an aerodrome and allow for information for takeoffs and landings. En-route weather forecasts, such as AIRMET and urgent pilot reports, are information covering the point of departure of an aircraft to its destination. Aviation oceanic forecasts deal with weather forecasts for long distance flights across the oceans and could be considered to be special cases of en-route weather forecasts. In the modern context, weather forecasts are indispensable to airline companies and the air-travelling public especially in improving their safety and comfort.

\section{Benefits of Aviation Weather Services in Terms of Fuel Cost Savings}

\subsection{General Literature on Fuel Cost Savings Using Various Management Strategies}

Fuel efficiency improvements in airline operations deal with the additional fuel that is normally carried during flights, routine maintenance of aircraft and airport management operations that could be reduced without sacrificing any aspects of safety especially for long haul flights (Avra et al., 2014). The International Air Transport Association (IATA) indicates that fuel bills constitute about a quarter of the annual operating costs of airlines (Avra et al., 2014).IATA suggests that in times of severe economic constraints, airlines may need to look for ways to reduce costs and improve fuel efficiency without sacrificing any aspects of safety. The cost of fuel has long been identified as one of the major overhead costs in the aviation industry making fuel efficiency an important subject for airline companies (Sarndal and Statton, 1975). O'Connor (2001) shows that fuel and labour are the two biggest direct operational costs of airlines. Doganis (2010) classifies labour as the first major cost and the fuel the second major one. Bazargan (2010) suggests that a surge in fuel prices imposes an enormous impact on airlines throughout the world stressing that fuel and crew constitute the major drivers of operating costs of airlines.

The practice of reducing the weight of an aircraft to save fuel is a well-established method of reducing fuel consumption. Fuel on board is a large component of weight to the aircraft (Cook et al., 2009) and means of reducing extra fuel on board based on high quality information available on en route weather and weather at landing airports is an important component of reducing airline operation costs (Mouton et al., 2015). In order to move an aircraft and cargo from one place to another, a certain minimum amount of fuel is required. A big reduction in this amount cannot be possible without investments in new fuel-efficient technology as argued by Mouton et al. (2015). They state that though fuel reduction is often spoken of in terms of percentage reduction in total fuel use, large percentage reductions in fuel use can be difficult to achieve in practice. Several empirical examples and practical business applications related to fuel cost savings have been used by various airlines. Of note is American Airlines which uses polish to combat corrosion instead of painting its airframes with the intended benefits of reduction in the weights of its planes and hence fuel cost reduction of the company. The returns from the fuel saved from reduced weight, is however partially offset by the increased maintenance cost required for polished aircraft (Airlines for America, 2011).

Anselmo (2004) indicates that Alaska Airlines, prior to the day departure, carefully counts the number of children going to be on-board and reduce the amount of fuel loaded if children fly instead of adults. Some airlines as part of operations have taken steps to reduce cabin weight by removing unnecessary items and replacing older and heavier carry-on board tools and equipment with relatively lighter tools and equipment. For example, according to American Airlines, replacing their 35-pound pilot kitbags with Apple iPads, annually saves the airline 400,000 gallons of jet fuel (Airlines for America, 2011). Likewise, JetBlue (2008) began a weight reduction campaign in 2006, by removing hundreds of pounds from each aircraft. For example, changing to radial tires on their E190 saved 128 pounds per plane. These adjustments, in addition to changes to galley provisioning and galley cart weights in 2007 are said to have saved 
over 950,000 gallons of fuel (JetBlue, 2008). British Airways, as reported by Anselmo (2004), sells in flight alcohol in plastic bottles instead of glass to cut down on weight and consequently fuel.

Instituting more frequent engine washing procedures according to Moody (2012) is another maintenance strategy to save fuel. Delta in 2011 washed 1,261 Delta engines and 33 contract engines, to which it attributed \$1.6 million in fuel cost savings. Operating a newer fleet with the latest technologies means less fuel consumption and reduced maintenance costs. Morrison et al (2010) suggest that retiring fuel inefficient aircraft and replacing them with more fuel efficient models can achieve additional fuel savings. This view is supported by Moody (2012) who reports that American and Alaskan Airlines in 2008 replaced many of its relatively inefficient MD-80 aircraft with more efficient Boeing 737-800 aircraft; the latter consume $18 \%$ less fuel.

Among the fuel-saving initiative for the aviation system is the possibility of holding aircraft at the gate, or the spot, until the point at which they can taxi unobstructed to the departure runway. The extent to which gate holding strategies have financial and environmental benefits hinges on the quantity of fuel that is consumed during surface operations. Hao et al. (2015) sought to utilize airline fuel consumption data to decompose taxi fuel use within nominal taxi time and in delayed taxi time for different types of aircraft in order to understand how much fuel is used in either taxi times. Their investigation revealed that the average potential fuel consumption reduction from doing away with taxi delay to be about $1 \%$ of total fuel consumption. A further analysis on an airport-by-airport basis, projects that, some airports could help the flights that operate at their airport reduce up to $2 \%$ of fuel consumption if delays were eliminated on their airfields. Further decomposing of surface operations into nominal and delayed taxi time to establish the relationship of both quantities of time on fuel burn reveals that fuel use that come as a result of a taxi out delay by a minute is less than the amount of fuel burned in a nominal taxi out delay over the same period of time (Hao et al., 2015).

In their work entitled Fuel Reduction for the Mobility Air Forces, Mouton et al. (2015) reviewed the literature on existing fuel reduction initiatives in the Air Force and the civilian industry and made several suggestions that could reduce fuel requirements for the operating of aircraft. These suggestions included the following: (1) the reduction of the weight of the aircraft to reduce the fuel required for a flight; this factor includes loading the required amounts of fuel based on weather forecasts (2) the optimal adjustment of both altitude and speed during flight to improve the fuel efficiency requiring use of weather information ( (3) the centre of gravity of an aircraft is affected by the placement of its cargo with more fuel burned with the forward movement of the centre of gravity hence the balancing of the cargo placement could reduce fuel use; (4) the purchase of newer aircraft that are lighter in weight and have more fuel efficient engines, this particular suggestion has been corroborated by the work of Anaman et al. (2000).

Abbey (2016) established that there was no significant relationship between the profitability of an airline and the size of its fleet. This conclusion applied to whether the airline used a hedging strategy to purchase fuel or it did not use hedging. Abbey (2016) claimed that the reduction in international crude oil prices over the last few years had not necessarily improved the profitability of those airline companies through the reduction in fuel costs largely due to the hedging strategies used by the airlines which committed them to the previously high prices of crude oil. Saving of fuel costs goes beyond lower fuel world oil prices to include the effective use of meteorological services. This factor is discussed in more details in the next section.

\subsection{Specific Literature on Fuel Cost Savings Using Aviation Weather Information}

More than any other mode of transportation, aviation is greatly affected by weather (Qualley, 1997). From thunderstorms and snow storms, to wind and fog as well as temperature and pressure extremes, every stage of air transport is susceptible to being affected by the weather conditions being experienced. Daily flights in the United States are numerous and commercial aviation in that country deals with these adverse types of weather regularly involving considerable cost to aviation companies (Qualley, 1997). Fairbanks et al. (1993) have documented a range of benefits to civil aviation from improved weather forecasts including for both short term and longer term forecasts. Fahey (1993) notes that benefits from improved weather information could be as high as $30 \%$ of the total fuel burned for some flights especially those involving relatively short travelling distances. Houle (2015) identifies several benefits of long range weather forecasts for the aviation industry. He indicates that the best long range weather forecasts as those provided between 24 to 48 hours before departure arguing that computer models generally produce forecasts for the three-hour range; these latter forecasts could be called the short-term weather forecasts. The major benefits of long range forecasts according to Houle (2015) include provision of a snapshot of high-level en-route conditions, determination of the need for overflight permits from national authorities, possibility of shortening the routes by avoiding severe turbulence and weather conditions and thus saving fuel. 
From operations research and systems simulation academic discipline, a model of airline operations can be constructed which places fuel cost reduction from improved weather information as a module or component in the overall system. For example, Zhang et al. (2013), using Petri nets theory and the top-down method in modelling aviation company fuel-efficient engineering system, build airline fuel-efficient models and airline management processes with the goal of saving fuel which allows for visual interactive decision making by managers. Similarly, developing the Cockpit Weather Information Needs (CWIN) system concept related on the difficulties pilots often encounter in obtaining a large volume of en route weather information, assimilating that data, using it to evaluate routes for weather avoidance, and to determine weather trends while en-route is a useful tool to reduce fuel costs. This concept involving en route weather information can save as much as $\$ 6$ million as argued by Phillips (1993). Further, by displaying virtually real-time weather information on the cockpit, the CWIN system would reduce voice communication errors and pilot workload.

During the en-route phase of flight, Jet stream winds and temperatures have a significant impact on fuel burn and on-time performance. Volcanic ash which is very harmful especially to aircraft engines, forces costly re-routes and this impacts adversely on fuel conservation. Reports of actual conditions from airports increasingly rely upon Automated Observing Systems (ASOS) (Qualley, 1997). What is important is that reports from these systems are accurate and representative of the weather conditions at an airport as a reduction or loss of trust in ASOS by its consumers would render great losses to airline operators such as carrying increased fuel and flight delays which impacts on the environment as well as passengers. The development of updated flight plans with respect to available weather information regarding changing wind and general weather conditions can enable aircraft to use fuel more efficiently.

In addition to the fuel required to complete a flight, FAA and other Air Navigation Service Providers regulate the amount of reserve fuel that must be added for any eventualities in the event that a flight may have to hold above an airport before landing because of congestion which would require the aircraft carrying extra fuel. Airlines load discretionary fuel for contingencies, beyond the minimum reserve fuel requirement of the Law, guided by the minimum amount of extra fuel required compared to the actual amounts of fuel that were required during the previous years (Karisch et al., 2012). Ayra et al. (2014), using the concept of discretionary fuel beyond the minimum required reserve fuel, argue that the need for airlines to load the extra discretionary fuel cannot be over emphasized as it reduces the probability that a flight would need to divert to an alternate airport since diversions come at extra costs of approximately $\$ 25000$ in direct operating costs. They argue that airlines must make a trade-off between the probability of diverting and the absolute cost of carrying discretionary fuel with the safety consideration being the most important consideration for the need to carry the extra discretionary fuel.

By quantifying the cost of fuel uplift for contingencies and highlighting the existing fuel benefit pool from reducing fuel uplift, Ryerson et al. (2015) estimated the benefit of an airline reducing fuel uplift beyond a certain level of uptake. They defined the cost side to include any possible increase in the number of diversions that the airline might experience as an aircraft was not likely to simply run out of fuel mid-air, but instead would more likely divert safely to another airport. It is often argued that diversions come with a significant cost as they are disruptive to the focal point of operations involving rescheduling take-offs and landings for various airlines using the airport. Ryerson et al. (2015) found that there were large benefits in fuel savings with the most conservative fuel loading practices suggesting that there existed benefits to be exploited with minimal impacts on airline operations by an analysis of various operating scenarios. The provision of very accurate information about the weather conditions of the destination airports and aerodromes as contained in the TAFs or TTFs is crucial in the optimal decision to carry discretionary fuel and/or to divert to an alternate airport or aerodrome. The findings of Ryerson et al. (2015) have been established in earlier studies by Leigh (1995), Leigh et al. (1998) and Anaman et al. (2000) for the Australian carrier, Qantas Airways.

\section{Other Benefits of Aviation Weather Information and Services}

\subsection{Weather Services and Airline Safety}

Airlines exist to provide freight and passenger services with flights planned and undertaken on timely basis according to the schedules of airports. The safety of an aircraft during flights is affected by weather-related hazards such as fog, poor visibility, clear air turbulence, mountain wave turbulence, thunderstorms, microbursts from thunderstorms, and wind shear; these hazards are the causes of many reported airline accidents around the world (Malala; undated). Weather is also known to be most important cause of flight delays and diversions. The issue of airline safety has been a pre-eminent policy concern (Chalk, 1987; Rose, 1992; Houle, 2015) with the acquisition of forecasts and information legally required for major civil flights in many countries (Robinson, 1989; Barnett and Higgins, 1989). Aviation is sensitive to the weather; no decision is taken without first putting the weather into consideration (Ewent Consortium, 2012; Eze, 2015, Pan Afircan News Agency, 2016). Safety has come under some threat as demand for air transport 
increases but with an unbalanced increase in airport capacities and facilities coupled with frequent extreme weather conditions being experienced across the world (Eze, 2015; Janic, 2000; Qualley, 1997).

In the United States, the civil aviation industry is regulated by the FAA. The National Transportation Safety Board (NTSB) of the United States identifies bad weather condition as a major cause of accidents experienced in the aviation industry with severe winds identified as the principal accident-causing weather phenomenon (NTSB, 2012). The commonest defining event involving accidents dealing with aircraft regulated by Part 121 laws in 2010 was turbulence during en route flights (NTSB, 2012). Most commercial aviation industry activities are regulated Federal Laws Parts 121 and 135 which refer to commercial aviation involving carrying of passengers and load (NTSB, 2012). Klein et al. (2009) identify bad weather as the most important source of unavoidable delays in the airline industry. They argue that when the weather is poorly forecast, especially forecast concerning the conditions at the destination or landing aerodrome, re-routing tends to occur and causes other problems related to the use of the airspace. Klein et al. (2009) also indicate that inaccurate weather forecasts account for about $12 \%$ of avoidable flight delays and $7 \%$ of avoidable flight cancellations in the United States alone costing the aviation industry about $\$ 330 \mathrm{~m}$ annually.

As argued by WMO (2014), the availability of accurate weather information helps pilots to avoid turbulence during flights and/or minimise the threats posed by severe turbulences, a major source of worry to the travelling public as severe turbulences in mid-air are often associated with passenger injuries and partial damage to the aircraft. Improvements in the forecast accuracy for upper air forecasts and incidence of turbulence have great impacts on aircraft engine performance and fuel efficiency which leads to improved profitability of airlines. The role of accurate weather information in relation to the safety of airline operations is stressed by Ahlstrom (2005) who argues for not just for improved accuracy of forecasts but also the issue of timely and updated information involving nowcasting satellite imagery tools; this suggestion is also strongly made by Malala (undated). Available evidence suggests general improvement of upper wind and temperature enroute weather forecasts over time. For example, Anaman et al. (1998, pp. 106-110) established a consistent annual improvement in the forecasts of upper wind and temperature at $250 \mathrm{hPa}$ pressure level when measured against radiosonde observations over the Australasian region of the globe over the period, 1972/72 to 1994/95 period using many observations and data points.

WMO (2014) shows that better weather forecasts also improve flight operations as unplanned flight deviations associated with bad weather are subsequently reduced. While better weather information helps to improve en-route flight operations in airports, WMO (2014) suggests that on-flight plan updates and altitudinal change information can help the management of airports to accurately schedule arrivals and departures of flights while minimising re-routing attributable to the weather. As indicated by WMO (2014) better weather information also aids airports in run-way management as flight schedules are then better planned to reduce the effects of weather related phenomena.

\subsection{Weather Services and Flight Planning}

As briefly indicated in the earlier sections, the planning of flights depends crucially on the availability of several types of weather forecasts and information. A flight plan is defined to include the route the crew will fly and specifies altitudes and speeds for the moving aircraft. It also provides projections on fuel usage during the flight and how much excess fuel to be carried along as prescribed within the safety regulations. By varying the route, altitudes, speeds, and amount of departure fuel, an effective flight plan can reduce fuel costs, time-based costs, over flight costs, and lost revenue from payload that could not be carried (Altus, 2009). Altus (2009) further argues that accurate, optimized flight plans can save airlines millions of gallons of fuel every year without forcing the airlines to compromise their schedules or service; this point is also noted by Ryerson et al. (2015). The potential savings of millions of gallons of fuel are due to the recognition that flight planning must include availability of accurate and timely weather information, the performance capability of the aircraft, other operational constraints of the airline company and other factor such as the physical conditions of the aerodrome.

Pilots depend on accurate and timely weather forecasts to plan their flights and ensure safety of the travelling public and the proper maintenance of aircraft and their equipment. For the airline company, accurate and timely weather forecasts allow for better planning for crew scheduling and passenger notification and the reduction of delays and diversions. WMO (2014) indicates that more than half of all air traffic delays within the United States National Airspace System are related to the weather. Many of these delays, as much as three-quarters of these delays have been described by FAA to due to inaccurate weather information (FAA, 2017). Evans et al. (2004) indicate that these delays often are the result of adverse weather conditions dictating that aircraft that approach the airspace of the landing airport be given priority to land. This priority assignment for aircraft nearing the destination aerodrome leads to the delay in the departure of aircraft which are stationed at the aerodrome preparing to take off. 
Von Gruenigen et al. (2014) stress that accurate weather services allow the aviation industry to achieve optimal air space management as air traffic controllers are able to make good decisions with regards to the maximisation of the use of air space capacity. This eliminates incidents of closures of parts of air space which leads to flight delays, cancellations and reductions in the number of flights. The importance of weather forecasts for flight planning is illustrated by Leigh et al. (1998) who argue that high accuracy of TAFs allow for reduction in fuel costs and additional benefits through reduced passenger frustration caused by delays and diversions. Gormley (2002) suggested that the FAA, working together with various meteorological agencies, was on the threshold of developing graphical weather products that could be sent to pilots at the cockpit of the aircraft due its increased focus on improving ways to collect, process, transmit and display weather information during flight planning and actual flights. One weakness of weather information for flight planning is that when pilots have a lot of information, their psychological make-up maybe affected causing them to make mistakes in decision making using that information (Illman, 1995). Illman (1995) advises pilots need to treat each piece of weather information they receive as a piece of a jig-saw puzzle which guides them to create a near perfect picture of expected and actual weather situations. While the forecasters indicate the likely or expected weather patterns enroute, the actual decision to travel or continue with the journey is made by the pilot.

\subsection{Weather Services and Airport Management}

The benefits of weather information are not only limited to airlines and their passengers, but also to airport airspace operations (Houle, 2015; Ahlstrom, 2005; Qualley, 1997). Roy et al. (2013) in studying air traffic management, show that weather information is an important factor to consider in determining and managing the capacity of flights within the airspace, thus, providing an indispensable tool for air traffic controllers and managers of airports. Wolfson and Clark (2006) note the gap between the demand for air transport services and the supply capacity. They argue that air traffic delays due to severe weather conditions and weather conditions at airports are constraints that need to be relaxed to allow this demand gap for air transport services to be met. Traffic delays are continuously being addressed with research into improving forecast systems so that traffic delays could be reduced in order to enhance benefits to airport managers.

Weather data conditions affect the rate at which air planes in an airport land and take-off (Roy et al., 2013). Dhal et al. (2013) study the problem of forecasting arrival rates of planes landing at airports and note the limitation of TAF weather information in managing airports; they suggest the use of forecasts derived from large scale numerical models integrated with regional scale modelling, as an additional tool to TAFs for the management of aircraft landings, departures and other functions of airports. Fabbian et al. (2007) explain that by using weather forecasts together with adopting the latest flight technology in planes, airlines could reduce unexpected costs. Klein et al. (2009) reveal from their study on airport capacity that when bad weather events are forecast and observed during the daytime, air traffic volumes at airports tend to be much affected than at night time when air traffic volumes are comparatively low.

Evans et al. (2004) discuss the impact of weather information on the capacity of a network of airports. According to Evans et al. (2004), a convective storm within one part of a network affects all parts of the network. They explain that, by rerouting flights to other parts of the network where the weather is much better, creating a situation where there are overloads, delays and congestions are experienced as flights can arrive but no departures can take-off. This then creates a situation where passengers get stranded at airports for about a few hours or some days depending on the prevailing weather condition. Bad weather experiences within an airport or within a network of airports affects airport operations in terms of gate space allocation, cargo handling and passenger management (Evans et al., 2004). FAA (2017) further adds that, when air traffic planners receive accurate weather information, they can effectively plan the traffic flow within their airspace and also make adequate plans on restricting flow when needed.

Ayra et al. (2014) sought to add to the literature by showing the need for integrating the different airline divisions to analyze and assess operational costs such as fuelling, delays, and airport diversions in a global manner. Taking into account all DOCs in their model, the study was able to prove successfully that, when the fuel loaded within an aircraft is optimised during the flight, diversion costs - in the form Air Traffic Flow Management - which are borne by alternative airports within a network is reduced considerably.

\subsection{Weather Services and Minimisation of Environmental Impacts}

Although the aggregate contribution of the aviation industry to worldwide greenhouse gas emissions is currently low, when emissions are calculated per passenger, the footprint is higher than any other human activity (Dessens et al., 2014). Nusser and Schmitt (1990) indicate that 3.2 tonnes of carbon dioxide are produced by commercial aircraft for each tonne of fuel consumed. Hence, when good weather information is available to airlines, they could reduce costs imposed on the natural environment through carrying of less fuel which results in less amounts of gaseous and particulate emissions from aircraft. The minimisation of environmental impacts from the use of improved weather 
services to the aviation industry is linked to the growth in the production of carbon dioxide emissions from the aviation industry which is estimated to be growing at about $4 \%$ per year by Lee et al (2009). However, Lee et al. (2009) argue that considerable reduction in the use of aviation fuel is possible but only with the introduction of radical technologies.

The incorporation of the aviation industry into international trading systems of emissions could lead to an overall decline in emissions; however proposals on these types of trading emissions have not been agreed to at the international level. Jardine (2005) explains that the distance travelled, freight load, the size and age of the aircraft also contribute to emissions. Therefore the reduction of greenhouse gases by aircraft should be taken from the perspective of a complete managerial analysis of the airline company including the possibility of acquiring newer and fuel-efficient aircraft and also including the role of improved weather forecasts in reducing fuel use.

Ryerson et al. (2015) provide a more recent study on the possibility to minimise the environmental impacts of the emissions of carbon dioxide by airlines through carrying less discretionary fuel which is possible based on the use of improved weather forecasts. As described in the earlier section of this paper, airlines normally carry excess contingency fuel to reduce the downside risk of diverting to an alternate airport when the weather is bad for landing at the designated aerodrome. Ryerson et al. (2015) analyse big sets of aviation weather data and data from a major United States airline. They show that loading of fuel is undertaken conservatively by the airline and that about $1.04 \%$ of the fuel used for an average flight is the result of the additional contingency fuel beyond a critical buffer. The estimate of yearly savings that could be made from a policy change by the airline on the carrying of additional contingency fuel with minimal risk was 338 million pounds of carbon dioxide (Ryerson et al., 2015). Anaman et al. (1998) show that there was a 6\% reduction in fuel consumption by the Qantas Airways Company due to use of TAFs for the 1993/94 financial year. This was equivalent to about 120 million litres of fuel or 95,256 tonnes of fuel and 304,820 tonnes less carbon dioxide emissions (Anaman et al., 1998).

\section{Costs and Direct Economic Benefits of Acquiring Weather Information and Services}

Qualley (1997) argues that the costs of acquiring weather information are quite expensive and increase the costs of airlines especially during turbulent economic conditions. Qualley (1997) estimates the monthly fees for the communication of upper air and surface data alone, per airline is approximately $\$ 6,000$. This added to that the cost of acquiring graphical weather data, National Weather Service DIFAX charts, lightning data, and radar and satellite imagery: approximately $\$ 7,000$. Leigh et al. (1998) indicate that the production of weather information may bring extra costs to the airline industry in terms of monies used as salary for technician and other equipment for receiving weather information. Gray (2015) estimated that the cost of weather information to airlines costs as much as £18 million per annum. This arguably may account for most airlines not resorting to aviation weather forecast and hence a ripple down adverse effect on fuel consumption through re-routing. This could result in a cost as high as $\$ 150,000$ in fuel cost as a result of diverting and costs incurred through cancellation running close to $\$ 40,000$ (Irrgang and McKinney, 1992).

The societal benefits of acquiring weather information for airlines often outweigh the societal costs involved in the production of this information even just from the safety perspective based on the considerable reduction of airline human fatalities and injuries in both absolute and relative terms over the last 100 years of air travel made possibly from improved equipment working together with improved weather forecasts. Specifically, at the company or airline level, the direct economic benefits tend to exceed the direct costs especially for large airlines which fully utilise the information. However, this evidence is not clear for small airlines as many small airlines around the world have been struggling with profitability.

Von Gruenigen et al. (2014), in their study on the economic value of weather services in Switzerland, conclude that the economic value accrued by airlines is high with airlines saving as much as between 14-22 million United States from receiving accurate weather information. The aviation industry in the United Kingdom saves an estimated $£ 400 \mathrm{~m}$ from weather services (Gray, 2015). Leviäkangas and Hautala (2009) establish that weather information saves the aviation industry in Finland about 14-24 million Euros a year. Leigh (1995) and Anaman et al. (2000) show that Qantas Airways Company pays annual fees to the Australian Bureau of Meteorology which are considerably less than what the company gets in terms of direct benefits from TAFs. Aviation weather services are often seen as commercial services to be charged fully to airline companies by the producing agencies which are usually publicly-owned entities which often supply various forms of weather information and service to the general public and selected businesses freely of charge. Nevertheless, it can be argued that some components of aviation weather services are not totally exclusively useful for only airline companies but contain public-good characteristics such as the use of improved weather information to eliminate air accidents over urban and densely-populated areas. This view suggests some subsidy for selected aviation weather services for the maximisation of the public good benefits to society. 


\section{Conclusions}

We have assembled a summary of the international literature published on the benefits of aviation weather services covering a period of 45 years from 1973 to 2017, and with emphasis on the literature over the last two decades, since the start of the $21^{\text {st }}$ Century AD. The benefits of aviation weather services ascertained from the literature review are those related to the reduction in the use of fuel and fuel-related operating costs, benefits derived from improved safety from the use of aviation weather services especially for the avoidance of turbulence and severe winds during en-route trips. Other benefits established from the literature review are those related to flight planning, airport management and the reduction of environmental impact through the emissions of less amounts of greenhouse gases resulting from prudent fuel policy allowed for by improved weather forecasts. Throughout the paper, we indicate the improvements in aviation weather services as a result of investments in technology and collaborations between local and international meteorological bodies all of which have enhanced the processes of observation and reporting of weather phenomena to the aviation industry.

We also report on the costs of accessing meteorological services by airline companies. This particular component of the review paper suggests that the costs for acquiring improved weather information by airlines was high and affects the precarious profitability of airlines especially during times of very high oil prices when airlines make much more stringent efforts to reduce their fuel costs. In general, the benefits of improved aviation weather services may well exceed the costs of acquiring these services given the indispensable role played by weather services in safe navigation within countries and across the globe. Yet, the use of improved weather services benefit airline companies beyond the reduction in fuel costs and safety to the reduction in delays and diversions which are themselves related to improved human happiness and welfare resulting from less frustration, stress and inconvenience associated with family and business lives. Hence there is a case for subsidising aviation weather services for struggling and small airlines, a point also made by the Montreal-based International Airline Transport Association.

Overall, despite aviation operations being highly sensitive to weather conditions, and the importance of weather information and services to the aviation industry, there is relatively little detailed quantitative analysis of economic value of aviation meteorological services beyond those of a few specific airline companies to the larger society. Many benefits reported in the literature are largely descriptive and back-of-the envelope simple estimation methods. It is imperative that the international aviation industry support more quantitative research works in this area in order to improve the information available to the general travelling public and especially policy makers who allocate taxpayer funds to national and international meteorological agencies. This is partly because large aspects of aviation meteorological services are public goods in nature and there is a limit of money to which airline and associated companies can be expected to pay for attributes and characteristics of weather services which are largely useful to the national and international community as quasi-public goods. Cost-sharing arrangements between the aviation industry and governments can be better formulated by improved and more detailed quantitative studies.

\section{Acknowledgments}

This paper was developed with the assistance from the Office of Research, Innovation and Development, University of Ghana, Legon, Accra, Ghana based on the research project entitled "Economic and Social Benefits of Meteorological Services in Ghana.

\section{References}

Abbey, D. R. (2016). The Relationship between Hedging and Airline Profitability. PhD Thesis, North Central University, San Diego, California.

Ahlstrom, U. (2005). Work Domain Analysis for Air Traffic Controller Weather Displays. Journal of Safety Research, 36(2), 159-169. https://doi.org/10.1016/j.jsr.2005.03.001

Air Transport Action Group (ATAG). (2016). Aviation Benefits beyond Borders. Geneva: ATAG.

Airlines for America. (2012). 2011 Economic Report. Washington, D.C.: Airlines for America.

Altus, S. (2009). Effective Flight Plans can Help Airlines Economize. Aero Quarterly, 3, 27-30.

Anaman, K. A., \& Lellyett, S.C. (1996a). A Contingent Valuation Study of the Public Weather Service in the Sydney Metropolitan Area. Economic Papers: A Journal of Applied Economics and Policy, 15(3), 64-77.

Anaman, K. A., \& Lellyett, S.C. (1996b). Assessment of the Benefits of an Enhanced Weather Information Service for the Cotton Industry in Australia. Meteorological Applications, 3(2), 127-135. https://doi.org/10.1002/met.5060030203 
Anaman, K. A., \& Lellyett, S.C. (1997). Evaluation of Use and Benefits of Public Weather and Climate Services by the Mining Industry in Queensland. Queensland Government Mining Journal, 98(1147), 56-61.

Anaman, K. A., Lellyett, S. C, \& Avsar, G.S. (2000). Assessing the Effect of Aviation Weather Forecasts on Fuel Expenditures of an International Airline. International Journal of Transport Economics, 27(2), 257-277.

Anaman, K. A., Lellyett, S. C., Drake, L., Leigh, R. J., Henderson-Sellers, A., Noar, P. F., Sullivan, P.J., \& Thampapillai, D. J. (1998). Benefits of Meteorological Services: Evidence of Recent Research in Australia. Meteorological Applications, 5(2), 103-115. https://doi.org/10.1017/S1350482798000668

Anselmo, J. C. (2004). Fuel Crisis Forces Airlines to Conserve, Drop by Drop. Aviation Week and Space Technology, $5(54)$.

Australian Bureau of Meteorology. (1981). Manual of Meteorology: Aviation Meteorology Part 2. Canberra: Australian Government Publishing House.

Australian Commonwealth Competitive Neutrality Complaints Office (ACCNCO). (2001). Meteorological Services to Aviation, Canberra: ACCNCO.

Aviation Weather Center (AWC). (2017a). Center Weather Advisory. Retrieved from https://www.aviationweather.gov/cwamis/help

Aviation Weather Centre (AWC). (2017b). Aviation Weather Overview. Washington, D.C: National Weather Service. Retrieved from https://www.aviationweather.gov/cwamis/help?page=over

Ayra, E. S., Insua, D. R., \& Cano, J. (2014). To Fuel or Not to Fuel? Is that the Question?. Journal of the American Statistical Association, 109(506), 465-476. https://doi.org/10.1080/01621459.2013.879060

Barnett, A., \& Higgins, M. (1989). Airline Safety: The Last Decade, Management Science, 35, 1-2. https://doi.org/10.1287/mnsc.35.1.1

Bazargan, M. (2010). Airline Operations and Scheduling (2nd ed.). Hampshire, United Kingdom: Ashgate Publishing Company.

Campos, M., Drake, L., \& Anaman, K.A. (1999). Impact of Tropical Cyclones Warning Information on Incomes of Commercial Tourist Accommodation Operators along the Queensland Coast". Economic Analysis and Policy, 29, 185-193.

Chalk, A. (1987). Market Forces and Commercial Aircraft Safety. Journal of Industrial Economics, 36, 61-81. https://doi.org/10.2307/2098597

Cook, A., Tanner, G. Williams, V., \& Meise, G. (2009). Dynamic Cost Indexing - Managing Airline Delay Costs. Journal of Air Transport Management, 15, 26-35. https://doi.org/10.1016/j.jairtraman.2008.07.001

Dessens, O., Köhler, M. O., Rogers, H. L., Jones, R. L., \& Pyle, J. A. (2014). Aviation and Climate Change. Transport Policy, 34, 14-20. https://doi.org/10.1016/j.tranpol.2014.02.014

Dhal, R., Roy, S., Taylor C., \& Wanke C. (2013). Forecasting Weather-Impacted Airport Capacities for Flow Contingency Management: Advanced Methods and Integration. Reston, Virginia: American Institute of Aeronautics and Astronautics.

Doganis, R. (2010). Flying off Course: The Economics of International Airlines (4th ed.). London: Routledge.

Evans, J. E., Allan, S., \& Robinson, M. (2004). Quantifying Delay Reduction Benefits for Aviation Convective Weather Decision Support Systems. In Proceedings of the 11th Conference on Aviation, Range, and Aerospace Meteorology, of the American Meteorological Society, Hyannis, Massachusetts, United States.

Ewent Consortium. (2012). Economic Value of Weather Forecasts on Transportation - Impacts of Weather Forecasts Quality Developments to the Economic Effects of Severe Weather. Retrieved 14 February 2017, from http://www.ewent.ttt.fi

Eze, C. (2015). Nigeria: Flying in the Rains. This Day, 26 June.

Fabbian, D., de Dear, R., \& Lellyett, S. (2007). Application of Artificial Neural Network Forecasts to Predict Fog at Canberra International Airport. Weather and Forecasting, 22(2), 372-381. https://doi.org/10.1175/WAF980.1

Fahey, T.H. (1993). Northwest Airlines' Atmospheric Hazards Advisory and Avoidance System, In Preprints of 5th International Conference on Aviation Weather Systems. Vienna, Virginia: American Meteorological Society. 
Fairbanks, M.C., Mitchell, D.G., \& Sweet, R.J.M. (1993). The Benefits to Aviation of Improved Meteorological Services. Final Report Prepared by the Smith System Engineering Limited for the Civil Aviation Authority, London, Great Britain.

Federal Aviation Administration (FAA). (2014) Retrieved from https://www.faa.gov/nextgen/programs/weather/faq/ Federal Aviation Administration (FAA). (2017). What is the Largest Cause of Delay in the National Airspace System? Washington, D.C: FAA. Retrieved 20 April 2017, from https:/www.faa.gov/nextgen/programs/weather/faq/

Ghana Meteorological Agency (GMET). (2017). Civil Aviation: 24-hour Forecasts for Ghana. Retrieved 8 May 2017, from http://www.meteo.gov.gh/website.index/php?option=com_content\&view=article\&id=52\&Itemid=74

Gormley, M. (2002). Data Link Cockpit Weather Comes of Age. Aviation Week, 91(4), 54.

Gray, M. (2015). Public Weather Service Value for Money Review. London: Public Weather Service Customer Group $\begin{array}{llll}\text { Secretariat } & \text { Office. } & \text { Retrieved from }\end{array}$ http://www.metoffice.gov.uk/media/pdf/9/4/PWS_Value_for_Money_Review_-_March_2015.pdf.

Guzman, R. D. (1999). The Role and Operation of National Meteorological and Hydrological Services. Bulletin of the World Meteorological Organization, 48(3), 291-297.

Hao, L., Ryerson, M., Kang, L., \& Hansen, M. (2015). Fuel Burn Impacts of Taxi-out Delay and their Implications for Gate-hold Benefits. In Proceedings 3rd International Conference on Research in Air Transportation, Lisbon, Portugal.

Houle, D. (2015). Benefits of Using Long-range Aviation Weather Forecasts. Operational Insight Blog, Houston, Texas: Universal Weather and Aviation Company (March 25).

Illman, P. E. (1995). The Pilot's Handbook of Aeronautical Knowledge (2nd ed.). New York: McGraw-Hill Professional.

India Meteorological Department (IMD). (2017). Civil Aviation - India's Official Weather Forecasts and Weather Radar and Satellite Imagery. Retrieved from http://www.indiaweather.gov.in/?page_id=262

International Airline Transport Association (IATA). (2017). Meteorological Charges: Airlines Should Pay Only a Fair Share of Cost Efficient Meteorological Services. Montreal: IATA. Retrieved 1 April 2017, from http://www.iata.org/policy/Documents/Meteorological-Charges.pf

Irrgang, M. E., \& McKinney, J. (1992). Analysis of Impact and Costs of Diversion. Technical Report for the Hudges Flight Dynamic and American Airlines.

Janic, M. (2000). An Assessment of Risk and Safety in Civil Aviation. Journal of Air Transport Management, 6(1), 43-50. https://doi.org/10.1016/S0969-6997(99)00021-6

Jardine, C. N. (2005). Calculating the Environmental Impact of Aviation Emissions. Oxford: Environmental Change Institute, Oxford University Centre for Environment.

JetBlue. (2008). Jet Responsibly Improving Our Communities and Our World. 2007 Environmental and Social Report. New York: Jet Blue Company.

Karisch, S. E., Altus, S. S., Stojković, G., \& Stojković, M. (2012). Operations Quantitative Problem Solving Methods in the Airline Industry: A Modeling Methodology Handbook Series. New York: Springer.

Klein, A., Kavoussi, S., \& Lee, R. S. (2009). Weather Forecast Accuracy: Study of Impact on Airport Capacity and Estimation of Avoidable Costs. In Proceedings of the Eighth USA/Europe Air Traffic Management Research and Development Seminar.

Lee, D. S., Fahey, D. W., Forster, P. M., Newton, P. J., Wit, R. C., Lim, L. L., ... Sausen, R. (2009). Aviation and Global Climate Change in the 21st century. Atmospheric Environment, 43(22), 3520-3537. https://doi.org/10.1016/j.atmosenv.2009.04.024

Leigh, R. J. (1995). Economic Benefits of Terminal Aerodrome Forecasts at Sydney Airport, Australia. Meteorological Applications, 2, 239-247. https://doi.org/10.1002/met.5060020307

Leigh, R. J. Drake, L., \& Thampapillai, D. J. (1998). An Economic Analysis of Terminal Aerodrome Forecasts with Special Reference to Sydney Airport. Journal of Transport Economics and Policy, 32(3), 377-392.

Leviäkangas, P., \& Hautala, R. (2009). Benefits and Value of Meteorological Information Services - The Case of the Finnish Meteorological Institute. Meteorological Applications, 16(3), 369-379. https://doi.org/10.1002/met.135 
Malala, R. (undated). The Impact of Weather on Aircraft Accidents. Pretoria: South African Weather Service.

Marks, R. E. (1980). The Value of "Almost" Perfect Weather Information to the Australian Tertiary Sector. Australian Journal of Management, 5(1-2), 67-85. https://doi.org/10.1177/031289628000500204

Moody, E. (2012). Focus on Fuel Savings: Airlines Use New Technology to Deliver Bigger-Than-Ever Fuel Savings. Aviation Week Network. Retrieved from http://www.aviationweek.com/awin/focus-fuel-savings

Morrison, J., Bonnefoy, P., Hansman, R. J., \& Sgouridis, S. (2010). Investigation of the Impacts of Effective Fuel Cost Increase on the U.S. Air Transportation Network and Fleet. In 10th AIAA Aviation Technology, Integration, and Operations Conference, Fort Worth, Texas.

Mouton, C. A., Powers, J. D., Romano, D. M., Guo, C., Bednarz, S., \& O'Connell, C. (2015). Fuel Reduction for the Mobility Air Forces. Monica, California: United States Air Force.

National Transportation Safety Board (NTSB). (2012). Review of U.S. Civil Aviation Accidents - Review of Aircraft Accidents Data 2010. Washington, D.C: NTSB.

Nusser, H.G., \& Schmitt, A. (1993). The Global Distribution of Air Traffic at High Altitudes, Related Fuel Consumption and Trends. In Schumann, U. (Ed.), Air Traffic and Environment - Background, Tendencies and Potential Global Atmospheric Effects (pp. 1-11).

O'Connor, W. E. (2001). An Introduction to Airline Economics. Greenwood Publishing Group.

Office of the Federal Coordinator for Meteorological Services and Supporting Research (OFCMSSR). (2014). Aviation Weather Services. Advisory Circular, AC 00-45G, Change 2. Washington, D.C.: National Oceanic and Atmospheric Administration and the United States Department of Commerce.

Office of the Federal Coordinator for Meteorological Services and Supporting Research (OFCMSSR). (2005). Surface Weather Observations and Reports Federal Meteorological Handbook 1. Washington, D.C.: National Oceanic and Atmospheric Administration and the United States Department of Commerce.

Pan African News Agency (PANA) (2016). South African Airways Cancels United States flights over Storms. Cape Town: PANA, 22 January.

Phillips, E. H. (1993). Upgraded Data Link May Cut Fuel and Rerouting Costs. Aviation Week and Space Technology, 139(23), 39-40.

Qantas Airways Corporation. (1993). Operational Policy - Fuel Policy. Sydney: Qantas Airways Corporation.

Qualley, W. (1997). Impact of Weather on the Use of Weather Information by Commercial Airline Operations. In Workshop on the Social and Economic Impacts of Weather, 2-4 April 1997, Boulder, Colorado, United States.

Robinson, P.J. (1989). The Influence of Weather on the Flight Operations at the Atlanta Hartsfield International $\begin{array}{llll}\text { Airport. Weather and } & \text { Forecasting, 461-468. }\end{array}$ https://doi.org/10.1175/1520-0434(1989)004<0461:TIOWOF>2.0.CO;2

Rose, N.L. (1992). Fear of Flying? Economic Analyses of Airline Safety. Journal of Economic Perspectives, 6(2), 75-94. https://doi.org/10.1257/jep.6.2.75

Roy, S., Dhal, R., Taylor, C., Wanke, C., Xue, M., \& Wan, Y. (2013). Generating Representative Weather-impact Futures for Strategic Traffic Flow Management: Airport Capacity Prediction. Reston, Virginia: American Institute of Aeronautics and Astronautics.

Ryerson, M. S., Hansen, M., Hao, L., \& Seelhorst, M. (2015). Landing on Empty: Estimating the Benefits from Reducing Fuel Uplift in US Civil Aviation. Environmental Research Letters, 10(9), 094002. https://doi.org/10.1088/1748-9326/10/9/094002

Sarndal, C-E., \& Statton, W.B. (1975). Factors Influencing Operating Costs in the Airline Industry. Journal of Transport Economics and Policy, 9(1), 67-88.

Sear, C. B., Tadesse, T., Bettany, B., Budgen, P., Copley, V., \& Griggs, D. (1996). The Presentation of Weather Information via the Media in Ethiopia. Meteorological Applications, 3(4), 295-300.

Shanahan, B.W. (1973). Verification of Terminal Aerodrome Forecasts Technical Report 2. Canberra: Australian Government Publishing House.

Shun, C.M., Lisk, I., McLeod, C., \& Johnston, K.L. (2009). Meteorological Services to Aviation. Bulletin, 58(2), Geneva: World Meteorological Organisation. 
South African Government Department of Environmental Affairs. (2016). South African Weather Service Act, 2001, Regulations Regarding Fees for the Provision of Aviation Meteorological Services. Government Gazette, Number 39919, 13 April.

Uganda National Meteorological Authority. (2017). Aeronautical Meteorological Services. Retrieved 15 April 2017, from http://www.unma.go.ug/index.php/aeroanutical-meteorology-services

Von Gruenigen, S., Willemse, S., \& Frei, T. (2014). Economic Value of Meteorological Services to Switzerland's Airlines: The Case of TAF at Zurich Airport. Weather, Climate, and Society, 6(2), 264-272. https://doi.org/10.1175/WCAS-D-12-00042.1

Wolfson, M.M., \& Clark, D.A. (2006). Advanced Aviation Weather Forecasts. Lincoln Laboratory Journal, 16(1), 31-58.

World Meteorological Organization (WMO). (2014). The Benefits of AMDAR to Meteorology and Aviation. World Meteorological Organization Integrated Observing System Technical Report 2014-1, Geneva: WMO.

World Meteorological Organization (WMO). (2015). Valuing Weather and Climate: Economic Assessment of Meteorological and Hydrological Services. Geneva: WMO.

Zhang, X., Zhao, M., Kuang, S. M., \& Du, Q. (2013). Research on Airline Company Fuel-Saving Model Based on Petri Network. Advanced Materials Research, 616, 1107-1110. 